\title{
Deposit Insurance and Banking Supervision in China: The Agenda Ahead
}

\author{
Haibo Yan $^{\mathrm{a}}$ and Ying Huang ${ }^{\mathrm{b}}$ \\ aPeople's Bank of China, 32 Chengfang Street, West District, Beijing, P.R. China \\ ${ }^{\mathrm{b}}$ Department of Economics and Finance, Northern Kentucky University, Nunn Drive, Highland Heights, \\ KY 41099, U.S.A. \\ E-mail: yhuang616@gmail.com
}

This paper proposes that the establishment of supervisory function in China's deposit insurance is an urgent task of the country's financial regulators and it becomes an indispensable component in a sound financial supervisory system. An important supplement to the banking regulatory system and aiming to protect depositors against financial losses caused by bankruptcy of financial institutions through a risk compensation mechanism, the implementation of supervisory function in deposit insurance helps to fulfill supervisory goals in the banking industry. Meanwhile, we argue that the supervisory responsibilities of the prospective deposit insurance agency in China are to some extent different from those of the existing banking regulatory institution, and therefore will not cause overlap in regulation or overuse of regulatory resources.

The Geneva Papers (2008) 33, 547-565. doi:10.1057/gpp.2008.12

Keywords: bank supervision; deposit insurance; financial stability; China

Jel classification: G21; G28

\section{Introduction}

In the wake of China's entry into the World Trade Organization in 2002, the domestic financial institutions have been taking on more risks and facing more challenges from their foreign rivals that were granted national treatment in China not long ago. ${ }^{1}$ The operational risks of the banking industry have also increased accordingly as the liberalization of China's financial sector has accelerated in recent years, leading to the phasing-out of those banking institutions that lack competitiveness. It is inevitable that some financial institutions will lose in the competition, which results in market exits, since as a whole China's domestic institutions are far behind most advanced international rivals in terms of quality of assets and profitability. ${ }^{2}$ Currently, China's financial institutions depend heavily on the central bank, the People's Bank of China (PBOC), for capital aid despite the fact that the Chinese government has put the restructuring of the banking sector in place since 2004. For example, $\mathrm{Yan}^{3}$ finds that

\footnotetext{
${ }^{1}$ In December 2006, foreign institutions were allowed access to the local currency business through locally incorporated subsidiaries, which marked the start of a tough competition between Chinese and foreign banks.

${ }^{2}$ Dobson and Kashyap (2006).

${ }^{3}$ Yan (2004).
} 
once a crisis occurs, PBOC shoulders the responsibility as the final provider of funds for both depositors and the concerned banks, which means the credit risks of the entire country are piled on the central bank. If some financial institutions encounter a crisis, the central bank has no option but to put more money into circulation at the expense of inflation and an oversupply of money.

The supervision of the banking sector was separated from the central bank with the establishment of China Banking Regulatory Commission (CBRC) in 2003, the country's banking watchdog. The effective supervision of CBRC certainly can lower the possibility of, or even fend off, the occurrence of financial crises. But such supervision cannot take the place of the supervisory function carried out by the prospective deposit insurance system, because financial supervision by banking authorities is intended as an anticipatory crisis-prevention measure. The deposit insurance system, on the other hand, will employ a combination of preventive measures instituted before the occurrence of crises and retrospective remedies. Furthermore, for a big country like China, which faces regional disparity and various types of banks (state-owned commercial banks (SOCBs), policy banks, ${ }^{4}$ joint-stock banks and credit cooperative unions, etc.), the regulatory duty of financial stability is less likely to be accomplished solely by the primary bank supervisory agency. Kahn and Santos ${ }^{5}$ argue that a single regulator will lead to insufficient bank monitoring and suboptimal bank investment in loans. It is useful to have both the central bank and the deposit insurer acting as lenders of last resort. Therefore, the establishment of supervisory function in China's prospective deposit insurance system similar to the U.S. Federal Deposit Insurance Corporate (FDIC) has increasingly become essential in dealing with future banking crises.

According to Demirgüc-Kunt et al. (2005), ${ }^{6}$ more and more countries have already adopted bank regulation and supervision in their deposit insurance system. DemirgücKunt et $\mathrm{al}^{7}$ find that a common goal of adopting deposit insurance in developing countries is to expand the reach of the banking system and to increase the flow of bank credit by minimizing depositor doubts about the banking system's ability to redeem depositor claims when funds are needed. Cull et al. ${ }^{8}$ use data on 58 countries and discover that in countries with better supervisory environments and comparatively sound legal systems, the deposit insurance scheme will be favorable to the healthy development of the financial industry. On the other hand, failure to incorporate supervisory measurements to overcome the adverse impact from the banking sector will cause paralysis of the entire financial system, thus disrupting of the benign cycle of the financial industry. The effective operation of deposit insurance is consummated

\footnotetext{
${ }^{4}$ Three policy banks, the Agricultural Development Bank of China, China Development Bank, and the Export-Import Bank of China, were established in 1994 to take over the government-directed spending functions of the four SOCBs. They are responsible for financing economic and trade development and state-invested projects.

${ }^{5}$ Kahn and Santos (2001).

${ }^{6}$ Demirgüc-Kunt et al. (2005).

${ }^{7}$ Demirgüc-Kunt et al. (2006).

${ }^{8}$ Cull et al. (2005).
} 
with a solid supervisory function; otherwise, the development of the financial industry will be hampered.

While there is a substantial body of applied research on deposit insurance, there is little research on the situation in China. In particular, the issue of deposit insurance has become a perennial source of investigation in China recently, more so with the recent transformation of China's four largest commercial banks' from wholly stateowned into shareholding banks. This paper is intended to fill the gap in this regard by investigating how to set up the deposit insurance system and its supervisory function under the current regulatory system, so that it enables the prospective deposit insurance system to fit China's current financial system, to adapt to the future development strategy of the financial supervisory system, and ultimately to meet the needs of the economic and financial development with Chinese characteristics.

We collect data mainly from various publications released by PBOC for our analysis. Otherwise, the data source is listed separately in the paper. The rest of the paper is organized as follows. The next section provides a brief discussion of lessons learned from the evolution of deposit insurance systems in the U.S. and Canada. The penultimate section focuses on issues in the Chinese deposit insurance arena, outlining current problems and explaining the features and benefits of, and guidelines for, implementing the supervisory function in deposit insurance. The final section offers concluding remarks.

\section{Evolution of the deposit insurance system}

\section{Defects of deposit insurance in early stages}

The purpose of the early deposit insurance is to protect depositors' interests and especially the majority of small depositors from suffering losses, so as to avoid runs on banks and ensuing bank panics. Therefore, after banks and other depository institutions are bankrupt or closed, deposit insurance will only guarantee the payment of insured deposits. This kind of "pay-box" deposit insurance system has played a positive role in safeguarding financial order and improving the confidence that the public has in the banking industry. But, under this system, the function of deposit insurance is entirely passive. That is, the deposit insurance scheme only sets in after the financial institution is bankrupt or closed, and is therefore powerless to take valid measures to prevent and intervene in bank failures to minimize losses. Usually the safety net for ailing banks is provided by regulatory institutions, the central bank or other government organs. For example, the Canadian Deposit Insurance Corporation (CDIC) was such an organization with the aforementioned functions before the 1980s.

In the late 1980s, the U.S. Savings \& Loan (S\&L) and banking crisis deepened. From 1980 to 1983,118 S\&L institutions went bankrupt, and losses amounted to US\$43 billion. Between 1980 and 1994, 1,617 FDIC-insured commercial banks and savings institutions became insolvent and got financial support from the FDIC, with the first biggest loss in 1988. ${ }^{9}$ Similarly, 25 Canadian insured depository institutions went bankrupt from 1982 to 1992, and the CDIC suffered enormous losses.

\footnotetext{
${ }^{9}$ Yan (2004).
} 


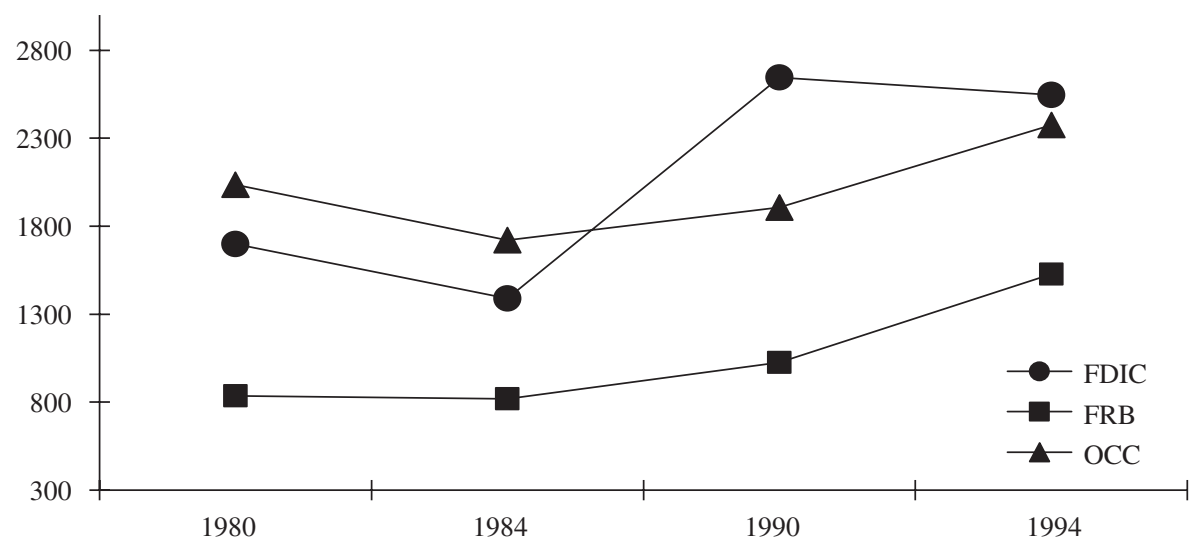

Figure 1. Number of examiners in the federal banking regulatory institutions. Data Source: FDIC collects the information based on the meetings of FRB, OCC and state banking regulatory institutions. FRB: Federal Reserve Bank. OCC: Office of the Comptroller of the Currency.

Analyzing the financial crises in these two countries, we see that apart from macroeconomic factors, such as a country's general political, economic, financial and legislative situation, a lack of financial supervision is another main contributor. Economic recessions in certain areas and industries led banks to undertake excessive risks. Regulators, such as the Federal Home Loan Bank Board, had serious problems in terms of regulation requirement and staffing, which ranged from lax regulation, lack of staff training, inadequate authorization to the Federal Savings and Loan Insurance Corporation, lack of necessary measurements, to the absence of timely adjustment, and hence the existence of a regulation gap and deficiency. As a result, the incentives of moral hazard increased. In addition, in the early 1980s the total number of examiners in the federal and state bank regulatory bodies kept shrinking, and the frequency of on-site examinations also dropped (see Figures 1 and 2). For instance, for the highest quality banks (with an average score of one in the CAMELS rating ${ }^{10}$ ) the number of days between on-site examinations soared from 456 days in 1980 to 845 days in 1986. The excessive undertaking of risks by profitable banks did not get under effective control, which further encouraged riskier lending by more depository institutions and eventually caused the outbreak of the crisis.

The introduction and reinforcement of regulatory system in deposit insurance

The investigation of the U.S. and Canadian banking crises of the 1980s and 90s reveals that banking supervision and regulation did not function as expected, and the deposit insurance system as a pure "pay-box" failed to promote financial stability. Problems seem to lie in two main areas. First, with only one regulator, there is a lack of

${ }^{10}$ It is a rating of six essential components of an institution's financial condition and operations, including capital adequacy, asset quality, management, earnings, liquidity and sensitivity to market risk. 


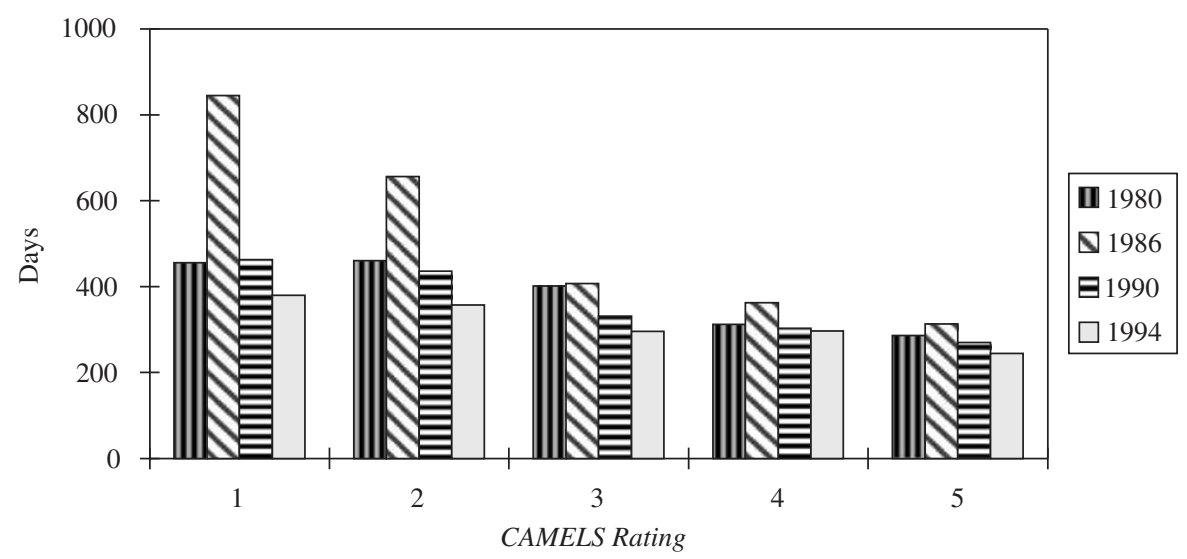

Figure 2. Time intervals between examinations on financial institutions with different CAMELS ratings. Data Source: FDIC, FRB and OCC.

restriction and surveillance, and the regulator is reluctant to close insolvent financial institutions, resulting in regulatory forbearance. Second, due to the existence of deposit insurance, insured financial institutions are inclined to engage in excessively risky behaviors. The profound lesson learned is that during a financial liberalization process it is necessary to adopt a diversified supervision apparatus to carry out steady and effective supervision on insured financial institutions that experience rapid growth. At the same time, more responsibilities and rights should be given to the deposit insurance institution, whose function should not be merely limited to a "paybox". Instead, the deposit insurance institution should have the authority/function to monitor and examine those insured financial institutions if necessary, take effective sanctions, mitigate moral hazard problems and minimize possible losses of the deposit insurance fund.

In 1987, Canada revised the legislation of the CDIC. The CDIC gained expanded legal and supervisory power, and took early intervening measures for risk management. The purpose of deposit insurance was becoming more explicit: offer insurance to protect depositors' interests; take measures to minimize losses; promote and safeguard financial stability; and assume an important role in helping member institutions operate smoothly and manage their finances. This indicated that for the first time active intervention was stressed and there was increased supervisory power in deposit insurance. In 1991, the passage of the Federal Deposit Insurance Corporation Improvement Act signified the introduction and enforcement of supervision and intervention measures on undercapitalized depository institutions, engendering innovations in the banking regulatory system. The main provisions to strengthen the FDIC's supervisory power include: (1) the least-cost method must be followed when the FDIC handles failed financial institutions (i.e. bringing minimal cost to the insurance fund); (2) prompt corrective action provisions require the FDIC to restrict certain lines of business or completely close down the "significantly undercapitalized" banks. 
552

It can be seen that the reforms in the U.S. and Canada focus on the minimization of costs and risks. To minimize costs in dealing with and closing down failed banks, deposit insurance institutions should participate in gleaning information about these banks so as to design a plan for asset maximization and liability minimization, and take effective measures to dispose of their assets and liabilities. On the other hand, risk minimization is also equivalent to cost minimization. It requires deposit insurance institutions to properly appraise and monitor risks undertaken by insured banks, and if necessary, take actions before banks actually fail, close them or take them over. In short, the goal is to reduce risks and losses to the utmost extent.

Deposit insurance institutions enjoy more power with the implementation of risk management. Along with bank regulators, they can decide the accession to and exit from the banking and deposit insurance system; institute and revise deposit insurance provisions; calculate deposit insurance premiums according to different risk categories; and take actions when certain risk indexes indicate problems (i.e. early intervention).

\section{Establishing a deposit insurance system with supervisory function in China}

The debate over whether to establish a deposit insurance system in China has been raging for a decade, but it is not until recent years that the conditions are believed to have matured. Deposits by individuals in China have topped 10 trillion yuan (US\$1.2 trillion) as of 2006 according to PBOC. The immaturity of the capital market means that they have few investment options, so the majority of Chinese have tended to put money in banks even when interest rates were slashed to the lowest point in years.

According to Okazaki, ${ }^{11}$ one of the serious problems with China's economy is the relatively inefficient allocation of funds throughout the financial system, which has been largely dominated by the state-owned banks. Figure 3 reveals that the big four SOCBs (namely, Bank of China (BOC), Industrial and Commercial Bank of China (ICBC), China Construction Bank (CCB) and Agricultural Bank of China) accounted for 55 percent and 54.9 percent of total assets and liabilities, respectively, of the whole banking sector at the end of 2003. ${ }^{12}$ Meanwhile, banks, especially the SOCBs, have generated huge non-performing assets. ${ }^{13}$ This was mainly because SOCBs were in charge of public finance and of supporting state-owned enterprises through providing funds without considering operating performance. Meanwhile, lax accounting rules, policy lending bias and poor corporate governance standards in SOCBs added to the severity of non-performing loans (NPLs) during this period. However, as a result of

\footnotetext{
${ }^{11}$ Okazaki (2007).

${ }^{12}$ Currently, the Chinese banking sector is dominated by SOCBs and joint-stock commercial banks (JSCBs).

${ }^{13}$ CBRC reports that the total amount of NPLs reached nearly 2 trillion yuan (US\$239.8 billion) at the end of September 2003, with an average NPL rate of 21.4 percent. As precursors to bank modernization, NPLs were transferred into four newly created asset management companies in 1999 and there were capital injections totaling \$45 billion to CCB and BOC from the central bank in 2004. The average NPL rate declined to 7.5 percent by 2006 . However, moral hazard problems ensued and many banks kept on lending recklessly. See Ma (2006) and Okazaki (2007) for detailed analyses.
} 


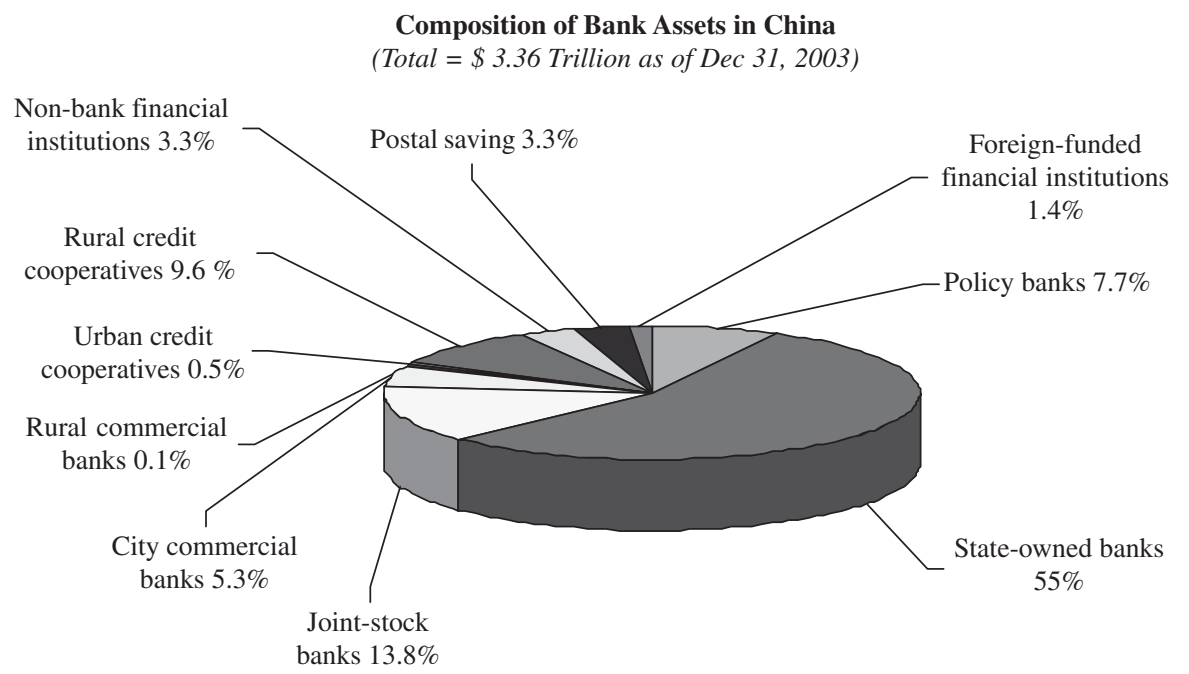

Composition of Bank Liabilities in China

(Total $=\$ 3.24$ Trillion as of Dec 31, 2003)

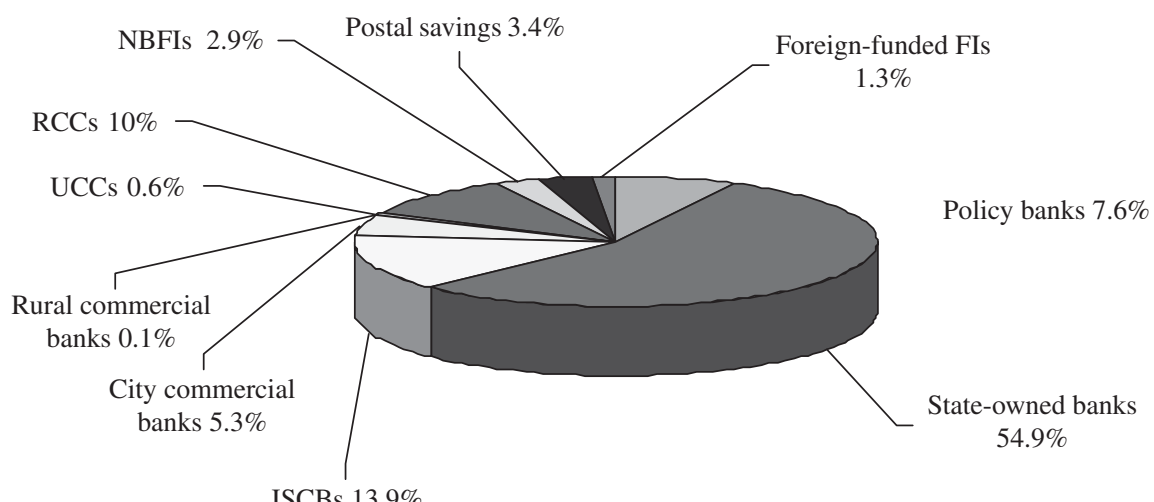

Figure 3. Compositions of bank assets and liabilities in China. Notes: The banking institutions include policy banks, state-owned commercial banks (SOCBs), joint stock commercial banks (JSCBs), city commercial banks, rural commercial banks, urban credit cooperatives (UCCs), rural credit cooperatives (RCCs), non-bank financial institutions (NBFI). The data are obtained from the CEIC database.

the Chinese government's intent to impose market pressures on directors and managers to bring the accuracy and transparency of their reporting up to international standards and to subject bank performance to market appraisals of efficiency and profitability, CCB, BOC and ICBC undertook initial public offerings (IPO) and were listed on foreign stock exchanges between October 2005 and May 2007. As such, China's SOCBs no longer remain dependent primarily on sovereign credit provided by 
the central bank, which used to keep deposits relatively safe during periods of panic withdrawals in the past. ${ }^{14}$

More importantly, as of 2006, China has 12 JSCBs, 113 city commercial banks, 78 urban credit cooperatives, 19,348 rural credit cooperatives and other financial institutions. ${ }^{15}$ These smaller financial institutions, which usually lack managerial skills, neglect basic principles of asset-liability management and even defy relevant laws and regulations, are easily exposed to risks since they have no support of sovereign credit. Although no financial crisis has yet broken out in China, mass withdrawals have occurred in a number of small- to medium-sized financial institutions in recent years, posing direct threats to the whole banking system. For instance, in 1998, the Hainan Development Bank, which had assets with face value of about $\$ 2$ billion, went bankrupt when people formed long queues at its branches after learning that the bank had acquired about 30 debt-laden urban credit cooperatives in Hainan Province. The bankruptcy of the Guangdong International Trust and Investment Corp. (GITIC), which defaulted on $\$ 4.7$ billion in debts in 1998, highlighted loopholes in financial regulation in China. The incident led to international criticism of GITIC for misleading creditors into believing that the central government had guaranteed GITIC's debt when it had not. The bankruptcy of China Agricultural Development Trust and Investment Company (with assets totaling 30.1 billion yuan) in 1997 is another high-risk case in the banking sector.

Table 1 shows a breakdown of all insured subsidiaries of publicly traded U.S. and foreign-based companies administered by three U.S. federal banking agencies in terms of insured depositories and insured depository assets. ${ }^{16}$ As shown in the table, although FDIC covers the largest number (9.1 percent) of publicly held insured institutions, the majority of FDIC-insured institutions fall into the medium- or smallsize categories as they hold only 11.2 percent of total insured depository assets. By comparison, as shown in Table 2, the current primary regulatory bodies in China consist of PBOC (mainly in charge of monetary and foreign-exchange policies), CBRC (separated from PBOC in 2003 to focus on banking monitoring and restructuring), China Insurance Regulatory Commission and China Securities Regulatory Commission. A deposit insurance system, one of the major risk-spreading and risk-absorbing supervisory measures used in Western developed economies, is expected to be established to mainly protect the interests of medium- or small-sized institutions and stabilize the financial system in China. It involves setting up a deposit insurance

${ }^{14}$ As the government's lending arm, SOCBs establish the primacy of policy objectives over commercial objectives, and they have little experience with managing risks and pricing capital. Even though three SOCBs are publicly listed, the government still maintains 70 percent ownership (see Okazaki, 2007, Table 3.12 ), making it difficult to create a truly commercial culture in the foreseeable future. International experience suggests that when the state still has a dominant or controlling share in a bank, it is very difficult to improve market discipline. Therefore, substantial reduction of state shares could be critical for successful reform. Complementary reforms in capital market will also be required for bank restructuring to be successful. Unless capital can be allocated by market forces, particularly by freely adjusting interest rates, banks will be unable to make their own lending decisions based on proper risk analysis.

${ }^{15}$ CBRC (2007).

${ }^{16}$ Burton and Seale (2005). 
Table 1 Insured subsidiaries of publicly traded U.S. and foreign-based companies by primary regulators in the U.S.

\begin{tabular}{lcccc}
\hline & $\begin{array}{c}\text { No. of insured } \\
\text { institutions }\end{array}$ & $\begin{array}{c}\text { Percentage of } \\
\text { insured } \\
\text { depositories }\end{array}$ & $\begin{array}{c}\text { Assets }(\$ b n) \\
\text { September 2004 }\end{array}$ & $\begin{array}{c}\text { Percentage of } \\
\text { insured assets }\end{array}$ \\
\hline Comptroller of the Currency (OCC) & 524 & 5.7 & $\$ 4,580$ & 46.3 \\
Federal Reserve (FR) & 274 & 3.0 & 1,792 & 18.1 \\
Federal Deposit Insurance Corp. (FDIC) & 828 & 9.1 & 1,109 & 11.2 \\
Total & 1,626 & 17.8 & $\$ 7,481$ & 75.6 \\
\hline
\end{tabular}

Source: Burton and Seale (2005), page 2.

agency, and aims to protect depositors against financial losses caused by bankruptcy of financial institutions through a risk compensation mechanism.

\section{Current problems in regulating China's financial institutions}

Despite the significant improvements over the last decade, China's financial supervision still lags far behind international regulatory standards due to the overall level of development of the banking sector and some managerial problems in the regulatory system. From the large amount of high-risk cases in the banking sector in recent years, it may seem that many problems stemmed from weak regulation or under-regulation, in particular a regulatory vacuum in many areas.

First, $\operatorname{Yan}^{17}$ argues that due to a lack of a standardized market exit mechanism in China, regulators exhibit procrastination and forbearance in handling failing financial institutions, hence inflicting great losses to the country. Regulatory authorities are more concerned about bank survival issues, resulting in regulatory forbearance and delay in closure. Failure to take corrective measures causes deterioration of assets in risky institutions, and ultimately magnifies costs.

With respect to regulation of bank capital adequacy management, after the shareholding reform of SOCBs, there are still 30 percent of depository financial institutions with very low capital adequacy rate. For these institutions with capital shortfalls, it is very difficult to take effective measures on their timely exit from the market. This is a clear indication of weak supervision and of the incapacity of forming effective deterrents to the managers of those institutions.

Second, the emergence of financial innovations, new markets and new forms of financial operations, along with the increase in credit to small and medium enterprises and microcredit, is making it harder for the old regulations to adapt to the new circumstances.

Third, staff shortages and backward regulatory philosophy have restricted regulation performances, which can hardly meet the requirements of the development of the banking sector. At present, the supervisory skills of Chinese financial

\footnotetext{
${ }^{17}$ Yan (2004).
} 
Table 2 Primary supervisory agencies in China

People's Bank of China

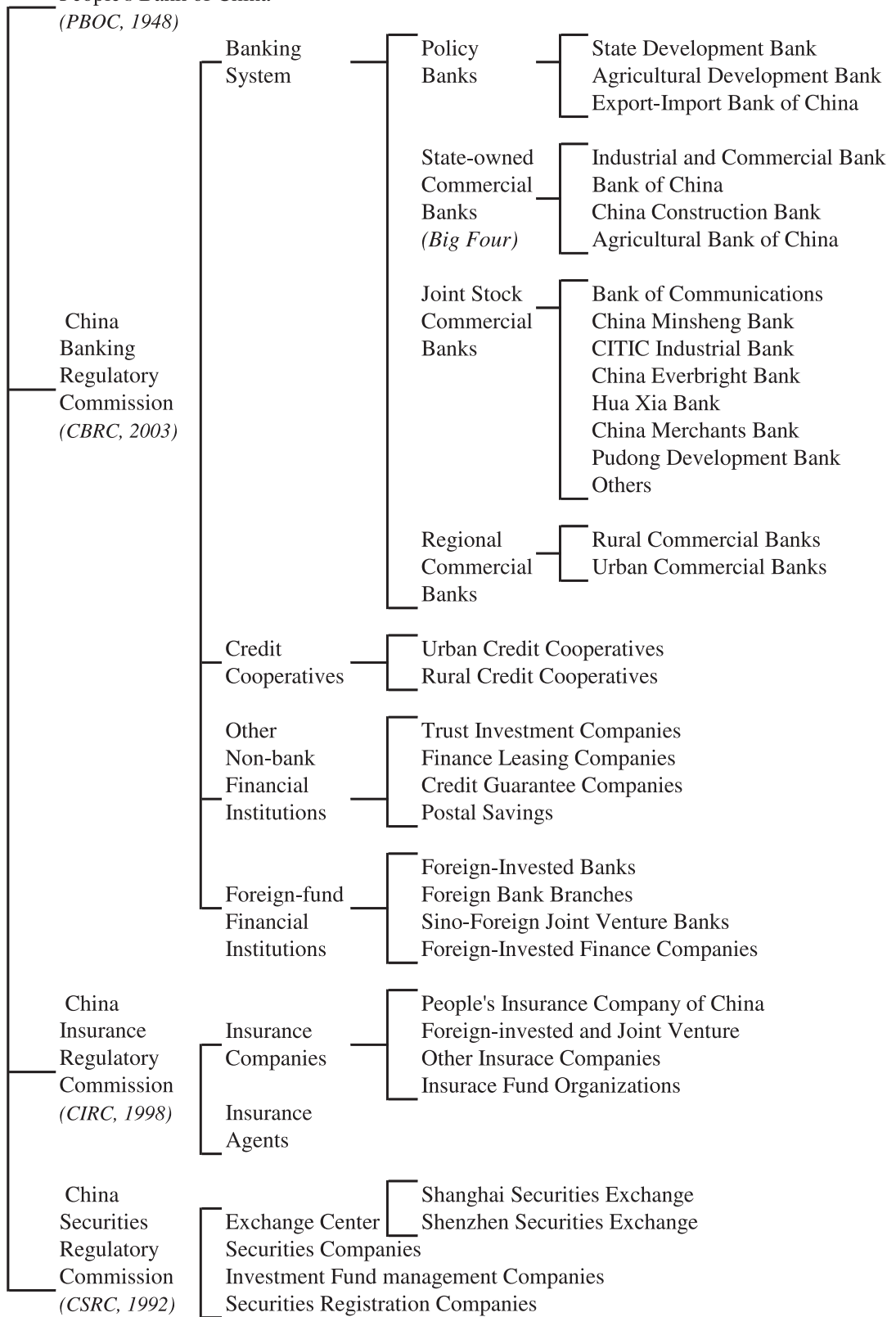


supervisory institutions, especially in the areas of financial derivatives, accounting practices and financial analysis, are still not up to par. ${ }^{18}$

\section{Urgent task of Chinese banking regulators}

As the liberalization of China's financial sector has accelerated in recent years, the operational risk of the industry has grown. The 1997 Asian financial crisis also highlights the urgency of setting up a system to ward off the financial crises and stabilize financial order. The supervision of the banking sector was separated from the central bank with the establishment of the CBRC in 2003. Currently, the focus of Chinese banking supervision practice has been gradually shifted from compliance management to both risk and compliance management. On the basis of full-scale implementation of the six-category classification system, CBRC also introduced the advanced "CAMELS + " rating system in 2005. ${ }^{19}$ Its supervision of the banking sector was further intensified.

In 2006, CBRC and its local offices dispatched 14,723 examination teams, and examined 69,179 financial institutions with a total business value of RMB 13.98 trillion. However, Figure 4 shows that these examinations mainly focus on 17 major commercial banks and three policy banks, which account for 82 percent of total cumulative workload. The smaller financial institutions, in particular 20,000 rural cooperative financial institutions, received a tiny fraction (3 percent) of the entire examination. It illustrates that there is plenty of room for improvement, which calls for the implementation of supervisory function in the prospective deposit insurance system.

In the course of supervision and regulation of the banking industry, some "state variables" 20 will change as anticipated (but not all of them), as it can be difficult to

${ }^{18}$ Chinese financial supervisory institutions have devoted considerable attention to human capital development in order to optimize the resources available to solve the problem. For example, in August 2005 and January 2006, the CBRC headquarters conducted two worldwide recruitment campaigns by means of interviews, written tests, specific exams and overall reviews. Through a "simply the best" selection process, 50 professionals including five department chief level directors joined the CBRC. As a result, the supervision staff can more accurately assess risk profiles of financial institutions, and play a better role in risk warning, identification and control.

19 According to CBRC's (2007) Annual Report, using CAMELS +, the banking institutions' capital adequacy, asset quality, management, earnings ability, liquidity, sensitivity to market risk and other factors can be assessed. These factors have been weighted as follows: capital adequacy 20 percent; asset quality 20 percent; management 25 percent; earnings 10 percent; liquidity 15 percent; and sensitivity to market risk 10 percent. Each dimension of CAMELS + rating includes both quantitative and qualitative factors, except for management quality. Each quantitative indicator and the determination of its corresponding value must be in accordance with the Core Indicators for the Risk Management of Commercial Banks in China, while each qualitative factor is determined based on the degree of compliance with relevant laws, supervisory rules and regulations.

${ }^{20}$ The supervisory and management target in a particular time period may be to make such assessment criterion as capital adequacy meet certain requirement. However, as a result of macroeconomic changes, the government modifies some industrial policy because of the influence of external factors, thus causing the failure of bank risk monitoring targets to meet the original anticipated requirement. In brief, state variables refer to certain monitoring indicators set by the banking regulatory bodies. 


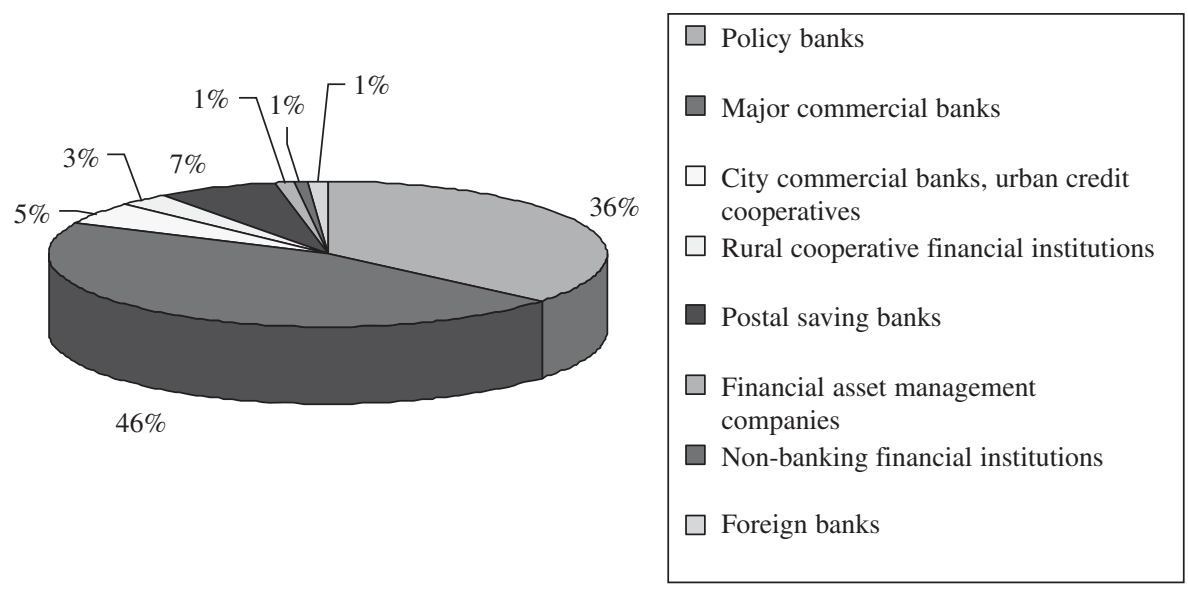

Figure 4. Cumulative workload of dispatched examination teams by banking institutions in China (2006). Source: CBRC Annual Report (2007).

meet original expectations. The main reasons are as follows. First, the target of financial supervision always changes with financial self-restructuring, and in principle the overall objective of financial activities has been capital appreciation, profit maximization and security. Therefore, regulators and regulated banks are in a constant state of dynamic contention. Second, the implementation of deposit insurance provides wide latitude for banks to seek unlimited profits. Because of the incentive predicament caused by principal-agent problems and inadequate supervision, there will be moral hazard and adverse selection problems. In pursuit of profits, the self-discipline of insured banks can easily fall apart due to any slight oversight. This was fully borne out by the U.S. savings and loans crisis in the 1980s.

Third, the uncertainty of financial activities and incomplete/asymmetric information tend to lead to poor coordination among regulators. Even though insured banks have the subjective desire to be self-disciplined, they would have to give it up or incur losses due to asymmetric information problems. Fourth, financial cycles are influenced by business cycles, and regulators' expectations may not keep up with the "phase transition of self-organization", that is, the phenomenon of a sudden change from boom to panic. As such, the scope of the financial regulators' control and regulation will be weakened and sabotaged. Fifth, the evolution, innovation and globalization of modern financial industries make it difficult for financial regulation to keep pace with the changing environment. The tendency of finance to move towards virtualization and independence, the special strategic status of finance in the economic and social stability, as well as the dynamic development trend, all induce regulators to sink into a passive position easily. As a result, regulatory measures can hardly be put in place, and regulators are facing greater difficulty, complexity, risk and challenge. These unfavorable factors pose tighter requirements on modern banking supervision. It impels bank regulators to enhance regulatory efficiency and improve their adaptability. 


\section{Benefits associated with multiple regulatory bodies}

Under a comprehensive and diversified banking supervisory system, things like inappropriately positioned regulators, bureaucracy, and lack of coordination, information exchange and communication, may lead to multiple policies, duplicate regulation and waste of supervision resources. Meanwhile, the inter-agency regulation competition can cause regulatory forbearance, which may result in inadequate supervision and render regulation a mere formality.

However, with a diversified banking system in the unique economy of China, it is very difficult to achieve all-round supervision by the primary banking regulator, namely CBRC. There is a regulatory vacuum or inadequate supervision due to lack of knowledge and insufficient staff training in a certain areas or in types of innovative products within a certain time period. In such cases, other regulatory agencies should be there to make up for this deficiency. Practical evidence has proved that the coexistence of several regulatory institutions is not necessarily a waste of resources or constitutes regulatory duplication. The key is whether regulators can share information and achieve regulation coordination. For instance, the CBRC was created in 2003 to fill the role of specialized regulation of an increasingly complex banking system. Although the PBOC had the organizational capacity and human capital to undertake this mission, it had little incentive to do so, with the highest priority given to inflation prevention and growth maintenance. ${ }^{21}$

While the primary banking supervisory system ${ }^{22}$ may save regulatory resources, reduce the costs of compliance and minimize overlapping regulation, it is difficult to shun the possibility of rent-seeking behaviors and mistakes. In the long run, funds that are saved in the regulatory process may not be efficient, because the closure of a bank arising from missing the opportunity of timely intervention will engender greater losses. Therefore, the government should establish balanced and restrictive mechanisms, give supervisory power to deposit insurance institutions, reduce inadequate supervision and regulatory vacuum, and improve regulation efficiency. In today's financial market, however, new financial products are surfacing continually, making financial risks more unpredictable in China. Financial panic may occur anytime and supervisory measures from banking authorities may be too late to contain any crisis.

The deposit insurance system in China, on the other hand, can counter the supervision weakness of existing financial authorities, thus forming an important line of defense. The introduction of supervisory function in deposit insurance is determined by the characteristics of the development of the banking industry in China. It is also an institutional arrangement to meet the challenges posed by the innovation in the banking industry, to ensure financial stability and to supplement the banking regulatory system. To the greatest extent, it overcomes the inherent defects in the deposit insurance system where lack of supervisory function brings about moral hazard problems. It also makes up for any oversight and deficiency in the monitoring

\footnotetext{
${ }^{21}$ Okazaki (2007).

${ }^{22}$ It refers to a bank supervision and management system where all banking institutions are supervised mainly by one banking supervisory body.
} 
Table 3 Diversified banking supervisory agencies in major countries

\begin{tabular}{ll}
\hline Country & Regulatory agency \\
\hline U.S.A. & 1. Federal Reserve Bank \\
& 2. Office of the Comptroller of the Currency \\
& 3. Federal Deposit Insurance Corporation \\
& 4. National Credit Union Administration \\
& 5. Office of Thrift Supervision \\
Canada & 6. State Banking Commissions \\
& 1. Office of the Superintendent of Financial Institutions \\
& 2. Bank of Canada \\
Germany & 3. Canada Deposit Insurance Corporation \\
France & 1. Provincial and Territorial Financial Regulators \\
& 2. Federal Banking Supervisory Office \\
& 1. Ministry of Finance \\
U.K. & 2. Banque de France \\
Japan & 3. National Credit Council \\
& 4. Banking Commission \\
1. Financial Services Authority & 2. Bank of England \\
1. Financial Supervisory Agency & 2. Bank of Japan \\
&
\end{tabular}

process, and strengthens the reliability of financial supervision and people's confidence in the financial industry.

Through its insurance business, the deposit insurer can regulate business activities of financial institutions. In the process, the deposit insurer examines financial institutions' documents, based on which it can either support or put pressure on them to reform their operations. By means of these measures, we believe that the deposit insurance system can effectively supplement the supervision of the Chinese financial system, forcing it to operate legally and in accordance with the rules of the banking administration in China.

By comparison, many countries in the world have already had multiple regulatory bodies with high efficiencies, and they are able to maintain long-term financial market security and stability (see Table 3). Whether information can be shared between regulatory agencies directly influences supervision coordination, efficiency and competition. Research shows that when there are multiple regulators, they may not have the inclination to share information. Accordingly, each regulator's monitoring scope and supervisory responsibilities should properly be arranged based on their information advantage. In addition, special systems and agencies should be established to address the issue of information sharing. For example, the United States has numerous supervisory agencies overseeing commercial banks and S\&L institutions. To prevent the occurrence of the aforementioned problem, in 1979 the Federal Financial Institutions Examination Council was established. It is an interagency body empowered to prescribe uniform principles, standards and report forms for the federal examination of financial institutions by the Board of Governors of the Federal 
Reserve Bank (FRB), FDIC, the National Credit Union Administration (NCUA), the Office of the Comptroller of the Currency (OCC), and the Office of Thrift Supervision. For decades the council has been operating efficiently, ensuring coordination among regulatory institutions, reducing unnecessary regulatory duplication and promoting uniformity in the supervision of financial institutions. This could be the solution to the challenges facing the Chinese banking industry.

Supervision competition becomes inevitable when several regulatory agencies coexist. However, the participation of deposit insurance agencies in the bank regulation process will alleviate regulatory forbearance, since these institutions will have to take their own interests into account and take early corrective measures. Moreover, joint supervision with banking regulators may protect the banking industry from over-regulation due to constraints arising from their mutual competition. On the other hand, deposit insurance agencies may help minimize regulation monopoly and rent-seeking opportunities, and mitigate moral hazard problems.

\section{Supervisory function of deposit insurance in China}

After gaining certain supervisory functions as its regulatory starting point, deposit insurance in China will have goals and methods that are distinct from those adopted by bank regulatory agencies. We suggest that the prospective deposit insurance agency perform its supervisory function in the following ways:

(1) Safeguarding self-interest when carrying out supervisory functions. As the deposit insurance institution bears losses of funds from bank failures by itself, it has more incentive to monitor or even shut down problem banks. This would inspire its regulatory initiative and responsibility to avoid regulatory forbearance. On the other hand, bank regulators are not responsible for any payment from bank failures. So the timing of bank closing and the responsibilities afterwards may well add to the costs of bank failures.

(2) Reducing the risk of moral hazard, enhancing financial security and stability. Moral hazard problems may bring relatively large negative impacts on the deposit insurance system and tend to be exacerbated in countries with weak institutional environments. ${ }^{23}$ For depository financial institutions, the implementation of deposit insurance will short-circuit runs on banks. Under asymmetric information, some institutions will take higher-risk investments in exchange for larger returns in their portfolios, thereby increasing the possibility of bankruptcy, which will be detrimental to financial stability. Deposit insurance protection for depositors makes them pay less attention to the risk of bank activities, lowering their vigilance to transfer funds to safer institutions, and weakening the binding forces that the market has on financial institutions. The study on deposit insurance system shows that a weak institutional environment and a lack of regulatory measures may easily induce moral hazard problems and trigger a financial crisis due to the principal-agent problem. ${ }^{24}$ Therefore,

\footnotetext{
${ }^{23}$ Demirgüc-Kunt and Kane (2002).

${ }^{24}$ For example, Cull et al. (2005).
} 
enforcement of appropriate regulations is the inevitable requirement of the effective functioning of the deposit insurance system.

(3) Regulating troubled banks, not touching conventional business of banking regulators. The aim of banking supervision and regulation is to achieve public policy objectives, the government's priority development strategies, universal protection of other participants' interests, and the security of the entire financial system. However, the goal of a deposit insurance institution is to reduce the possibility of failure of depositary institutions, detect problems earlier to avoid the spreading of the crisis, improve the effectiveness and efficiency of deposit insurance, and minimize losses. Therefore, banking regulators are primarily responsible for the day-to-day supervision of bank compliance and risk control, maintaining stable operation of the entire banking industry. When problems are discovered in a bank's operation, the deposit insurance institution will intervene and conduct full-scale risk control.

(4) Actively taking early corrective measures, combining appropriate market exit procedures to give failed banks certain options and reducing regulatory forbearance in closing down failed banks. Banking regulators tend to implement remedial measures on ailing banks. However, lack of determination often makes them hesitant in the process of helping troubled financial institutions.

The essence of taking early corrective measures by deposit insurance agencies can be boiled down to the early detection and resolution of operational problems of depository financial institutions. When the bank in trouble still has the ability to absorb losses, using early corrective measures will protect the deposit insurance system and taxpayers, thus lowering the deposit insurance fund's risk of long-term loss. The determination of deposit insurance to close the troubled bank will force bank regulators to consider and accept the fact that the bank is beyond rescue and must be closed. It accelerates the exit of the problem bank from the market and minimizes losses. The early corrective measure is an incentive-compatible regulatory strategy. It also optimizes the entire financial incentive-compatible regulatory environment, which is in line with the least-cost/loss principle. It provides the troubled bank not only with the freedom to close down, but also with a certain leeway, hence more incentive for the bank to choose the best outcome.

(5) Comprehensive monitoring of failed depository institutions. In handling failed depository institutions, deposit insurance agencies commonly adopt the purchase and assumption method, deposit payoffs and open bank assistance, in which the assistance can take the form of loans, subsidies, purchasing assets or other forms of debt commitments. Regardless of the method, the deposit insurance institution will make careful arrangements of the resolution to ensure the effective use of funds.

\section{Guidelines on supervisory function and scope of deposit insurance}

Weak financial supervision and shaky market restrictive mechanisms necessitate the augmentation of regulatory bodies and the intensification of supervisory control. We believe that the supervisory function and scope of deposit insurance in China should be based on China's actual situation, forming an effective division of labor and 
cooperation with existing regulatory bodies. This is mainly manifested in the following guidelines:

(1) Vigorously developing an off-site examination system. Through the establishment of some statistical models, the deposit insurance institution along with other rating agencies can analyze and ascertain banks' financial conditions by examining periodic reports filed by banks and assessment reports issued by other regulatory bodies.

(2) Paying attention to the supervision of small-sized insured financial institutions. Small and medium financial institutions in $\mathrm{China}^{25}$ tend to have various types of problems, for example holding assets of a smaller scale, capital adequacy ratios falling short of the minimum requirement of the Basel Accord, incomplete corporate governance structure or weak risk management capacity. Therefore, these institutions could face more severe survival pressures, and their failure probability is relatively higher. To improve the efficacy of supervision, supervision of such institutions calls for closer communication and collaborative examination from the prospective deposit insurance agency and the primary banking regulator.

(3) Increasing supervisory transparency on deposit insurance. A transparent information disclosure system on deposit insurance can enhance the public's understanding and knowledge of banking supervision authority, which in turn can contribute to public confidence in the banking industry.

(4) Establishing a necessary information-sharing mechanism and a clear division of work and focus. This requires mutual trust and close cooperation and coordination between banking regulators such as $\mathrm{CBRC}$ and deposit insurance agencies. The two parties should jointly develop a "guide to risk intervention", explicitly defining their respective responsibilities and the timing of intervention, when a certain bank falls into the "shaky" category. Regulators should establish a high-level bilateral communication mechanism, conduct joint on-site examinations and actively participate in the formulation of regulatory standards of the banking industry. ${ }^{26}$

\section{Conclusions}

In light of the need to keep pace with rapid changes in China's banking industry, a deposit insurance system is about to be launched in the near future. Different types of financial institutions in China are facing great disparity in terms of risks and internal

\footnotetext{
${ }^{25}$ Such as urban commercial banks, rural commercial banks, rural cooperative banks and rural credit cooperatives, etc.

${ }^{26}$ Regulators should also clearly specify joint and individual on-site examinations in terms of time coordination. When one regulatory agency downgrades the regulatory target, it needs to share the information with the other regulatory agency. After finishing an examination and preparing a meeting with the management of the examinee to reach final regulatory conclusions, one regulatory body can let the other participate in these meetings. One regulatory body can monitor if a financial institution complies with the laws and rules set by the other regulatory body. An examination report generated by one regulatory body should be copied to the other agency, and the examinee should also be informed of this process. When one regulatory body intends to take actions on the examinee, it should make the other regulatory body aware of it.
} 
control mechanisms. At the same time, the financial market exit mechanism is incomplete. Both financial supervisory mechanisms and institutions have yet to be further improved and strengthened. Therefore, a deposit insurance system in China will be designed not merely to protect small depositors' interests, but to create a sound and standardized investor protection system and a market exit mechanism for financial institutions. It will enhance the financial safety net, improve the banking regulatory system and ultimately achieve the objective of financial stability on the basis of market-based principles.

The design of the deposit insurance system in China should be such that it is beyond a simple "pay-box", as there are a lot of factors to take into consideration, including various forms of banks in the banking system, the status quo of banking regulation, risk exposures in bank operations, and the uncertainty of rescuing funds. It is anticipated that the deposit insurance agency will put limited funds into the most reasonable usage, minimize the loss of deposit insurance fund, increase regulatory incentive compatibility and effectiveness, and make up for inadequate supervision. Empowered with a supervisory function, deposit insurance will be able to properly combine responsibilities, rights, and interests, so as to reach the goal of protecting the interests of depositors and taxpayers in China.

In sum, we propose the implementation of supervisory function in the prospective deposit insurance system in China. Regardless of the form it takes, it is requisite for a sound Chinese financial supervisory system. It will largely compensate for the inadequacy of existing regulations, further promote the banking regulatory incentive compatibility and upgrade the existing banking regulatory efficiency.

\section{Acknowledgements}

We thank Feng Guo for helpful comments. This paper's findings, interpretations and conclusions are those of the authors and do not necessarily represent the views of the People's Bank of China.

\section{References}

Burton, S. and Seale, G. (2005) 'A survey of current and potential uses of market data by the FDIC', FDIC Banking Review 17: 1-17.

China Banking Regulatory Commission (CBRC) (2007) Annual Report, Beijing.

Cull, R., Senbet, L.W. and Sorge, M. (2005) 'Deposit insurance and financial development', Journal of Money, Credit \& Banking 37: 43-82.

Demirgüc-Kunt, A. and Kane, E.J. (2002) ‘Deposit insurance around the globe: where does it work?' Journal of Economic Perspectives 16: 175-195.

Demirgüç-Kunt, A., Kane, E.J. and Laeven, L. (2006) Deposit insurance design and implementation: Policy lessons from research and practice, The World Bank's Policy Research Working Series, No.3969, Washington, DC.

Demirgüc-Kunt, A., Karacaovali, B. and Laeven, L. (2005) Deposit insurance around the world: $A$ comprehensive database, The World Bank's Policy Research Working Series, No.3628, Washington, DC.

Dobson, W. and Kashyap, A. (2006) 'The contradiction in China's gradualist banking reforms', Brookings Papers on Economic Activity 2: 103-162.

Kahn, C.M. and Santos, J.A. (2001) Allocating banking regulatory powers: Lender of last resort, deposit insurance and supervision, Bank for International Settlements Working papers, No.102, Basel.

Ma, G. (2006) 'Sharing China's bank restructuring bill', China and World Economy 14: 19-37. 
Okazaki, K. (2007) Banking system reform in China: The challenges of moving toward a market-oriented economy, RAND Occasional Paper, National Security Research Division, Santa Monica, CA.

Yan, H.B. (2004) 'The difficulties and choices in establishing Chinese deposit insurance system', Finance Research 11: 33-40 (in Chinese).

\section{Author the Authors}

Haibo Yan is the director of Deposit Insurance Division at the People's Bank of China. Previously, he was the executive managing director at China Everbright Financial Asset Management (Hong Kong) Ltd. during 2000-2002.

Ying Huang is the corresponding author. She is an assistant professor of finance at Northern Kentucky University. Her research interests include derivatives, corporate finance, and international finance. Her work has been published in a wide variety of scholarly finance and economics journals. Dr. Huang earned her Ph.D. in financial economics from the City University of New York and a B.A. from Wuhan University of Science and Technology in China. 